\title{
Insight Into The Lives Of Female Nurses In Lahore: An In Depth Analysis
}

\author{
Lubna Karim Naz \\ Center for Media and Communication Studies \\ University of Gujrat \\ Umar Rafique \\ Department of Sociology \\ University of Gujrat
}

\begin{abstract}
Present study aims to understand the life of female nurses working in public sector hospitals in Pakistan. An effort is being made to collect maximum amount of information about the nurses' lives. This study is conducted in one of the largest public sector hospital in Lahore. Snowball sampling technique has been adopted for collecting data from the nurses. 20 in depth interviews have been conducted. This qualitative data has been analyzed by the Hesse-Biber \& leavy (2006) technique for conducting a rigorous analysis of the data. Three categories were emerged in the collected data. Life at hospital, Societal Response toward nurses and views about government policies. Toughness of job, issues of harassment, low salaries, daunting respect and honor, Issues in marriage prospects, lack of any service structure were the common themes under these categories. This study has immense importance as it has added more in existing knowledge about the nurses' lives. Present study reveals other issues of their lives as well other than harassment issues. Recommendations were being made to improve the lives of nurses.
\end{abstract}

Keywords: Nurses, Harassment, Government Policies, Lahore, Respect \& Honor.

$$
\begin{aligned}
& \text { تلخيص }
\end{aligned}
$$

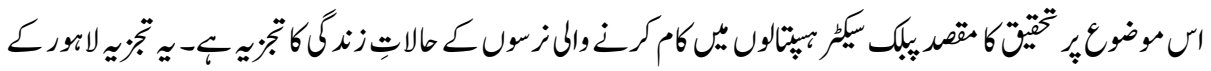

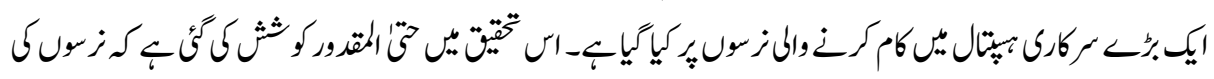

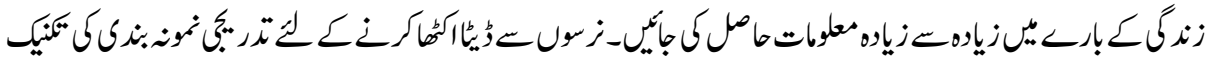

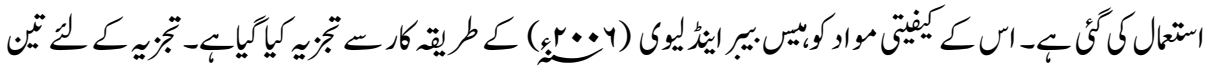

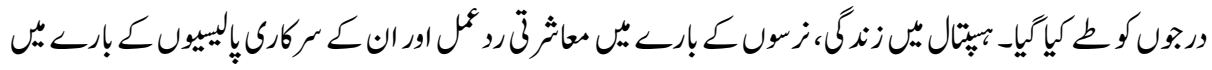

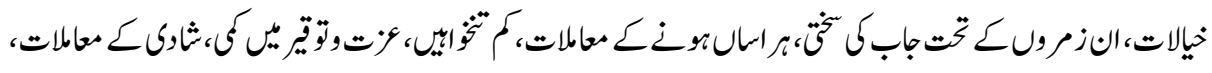

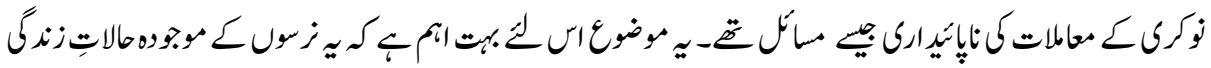




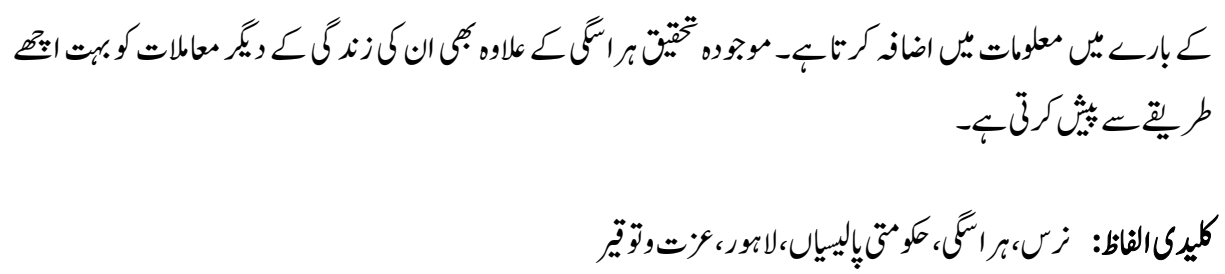

\section{Introduction}

With the rapidly modernizing world females are increasingly participating in labor force for the development and progress of their countries. In Pakistan as well, females slowly but steady are increasingly getting into the labor market. Recent World Bank 2014 statistics 25\% females are participating in the labor force World Bank (2014). They are getting into different fields like medical, Teaching, Banking and corporate sectors etc. One of the oldest and traditional jobs which females have adopted in all the times that is a profession of caring the patients commonly known as Nursing. Their role has immense importance throughout the history and in medical care. $80 \%$ of total health care is given by nurses. If a health system has registered and trained nursing staff, that health system goes successful (Royal College of Nursing, 2008).

Different countries have promoted this field a lot. As they consider nursing staff an important pillar of health care system so they have developed specified trainings, diplomas, and certifications for them and develop them to the extent where they can actively and efficiently work with the doctors for the health promotion. For the said purpose they have also given a secure work environment, a job structure and above all a respectable status in society.

But nursing as remaining a females' dominated profession have problems and concerns in most of the developing countries where there is still greater levels of gender inequality prevails and women have to work a lot for achieving a respectable endorsement as a working women. This issue always remains critical which leads to a decrease in the females' labor force participation as well in these countries (Jayachandran, 2015). Their problems, issues and concerns do vary in the type of job they are doing.

Pakistan is also facing gender related serious problems. Pakistan is on $147^{\text {th }}$ number on Gender Inequality Index which is a lowest position in the Gender related human development rating Human Development Reports, UNDP (2015). Because of a patriarchal society working women have to go to an extra mile in getting themselves well adjusted breaking all the shackles of society. Even one of the very basic challenges faced by Pakistani women is their right to work in a safe and respectable environment (Ferdoos, 2005). According to an estimate at least 50 percent of women in public sector face harassment at work place in Pakistan (NCFJAP, 2007). 
In a similar vein, nurses are also facing a tough time in the hospitals. American Nursing Association (2016) defines nursing as "It is the protection, promotion, and optimization of health and abilities, prevention of illness and injury, facilitation of healing, alleviation of suffering through the diagnosis and treatment of human response, and advocacy in the care of individuals, families, groups, communities, and populations." According to the Royal College of Nursing UK, the use of clinical judgment in the provision of care to enable people to improve, maintain, or recover health, to cope with health problems, and to achieve the best possible quality of life, whatever their disease or disability, until death. So simply nursing is a profession which aims at helping patients to cope with their diseases and to remain healthy. It is also clear from the above statements that why is it called the noble profession because its main duty is to help the patients to improve their health and to take care of them.

As nursing belongs to a white color profession, have virtually no any power and authority in our society and as mostly females are into this profession, so they face a tough situation in our society. They are being named as "sex workers" "prostitutes" harassed and threaten by the people. They have not being given proper respect and honor which they deserve (Yusufzai, 2006).

This is also evident from the frequent strikes and protests of the nursing staff in Pakistan, demanding for their rights, service structure, and a peaceful and comfortable work environment. This all scenario calls for a serious investigation into the lives of nurses. In this paper an effort is being made to understand the lives of nurses that how they are spending their lives in hospitals? What are their concerns and issues? What is societal response toward them? These all questions are being discussed in this paper.

\section{Objectives of Study}

Following are the important objectives of the present study.

- To study the lives of nurses extensively.

- To understand the problem which nurses face at work place

- To know what sort of response nurses get from the society.

- To know nurses' perspective on the government policies regarding nurses.

\section{Significance of the Study}

This study has manifolds importance. This helps to understand the realities of nurses' lives on many different levels. First of all this paper calls for attention to the working women of our society. What kind of problems and issues working women are facing in our society. 
Second significant aspect of this study is that a plenty of research work has done on doctors' life, their duties etc. But very limited literature gives coverage to the lives of nurses; a coverage which can reveal some facts about their lives. As nurses are very important for any health care system but they are not given their due share. They work so hard but their salaries and other incentives are not in accordance to the hard work which they perform. This is evident from the frequent strikes of the nursing staff of the province Punjab demanding for their rights and for having a concrete service structure. In this study researchers want to analyze the existing situation of government hospital from the perspective of nurses. How are they spending their lives? What are the problems which they are facing there? What are their views regarding government policies for nurses?

Infect this study is an investigation into the life of nurses. This study will add into the knowledge about nurses in Pakistan. It will give an opportunity to researchers as well as readers an understanding of nurses' lives. It will give us an opportunity to realize the importance of nurses in hospitals. This study can also air some voice for the rights of the nurses. This study can also lead to the debate over the role nurses are performing and the reward which they must be given in return.

Last but not least, this study has also importance as to give an insight in the lives of working women, having white color jobs. So this is a significant addition in the gender literature and about the situation of working women in our society belong to middle class, white color professions.

\section{Problem Statement}

Present study aims to understand the lives of nurses working in the public hospitals of city Lahore in Punjab, Pakistan. Nurses are facing a tough time in our society. This is evident from the frequent strikes of the nurses and the hectic routine of nursing staff in public hospitals of Pakistan.

This study will reveal the facts about the lives of nurses in following dimensions. i) This study will reveal the problems which nurses face in hospitals. ii) It will also help to understand the nurses' perspective on the government policies regarding nurses. iii) Lastly it will also explain the problems which nurses face in the society.

\section{Literature Review}

Following are some of the studies which have been already conducted on nurses' lives. Malik et al. (2014) analyzed the relationship between sexual harassment, self esteem and job satisfaction among the in-training nurses in four hospitals in Lahore and Islamabad. 120 females participated in this research. Data was collected using Sexual harassment 
Experience Questionnaire, Self esteem scale and Job satisfaction scale. Pearson Correlation and regression analysis shows that sexual harassment is the significant predictor of low self esteem and low job satisfaction among in training female nurses. It has been recommended that smooth work environment free from all kinds of sexual harassment must be needed for providing best health care services to the public.

Malik \& Farooqi (2014) conducted a research to examine the impact of general and sexual harassment on post traumatic stress symptoms. 300 medical staff, constituted the sample which was drawn from five public hospitals of Lahore city. A significant positive relationship has been found in general and sexual harassment and post traumatic stress symptoms. Awareness must be raised in order to reduce work place harassment and its negative consequences.

Somani \& Khowaja (2012) in their case report discuss the devastating effects of workplace violence. They were of the view that workplace violence among nurses is common in every health care setting. Nurses do not get enough respect and honor in Pakistani society which leads to workplace violence towards nurses which includes both psychological and physical violence. There are many incidences of reported and unreported rape, unwanted sexual deeds, work place bullying and other related issues from patients, family members and other paramedical staff. According to the researchers these incidences went unreported because of the fear ad more disrespect in society. A safe work environment is direly needed for the nurses satisfaction and their better performance.

Mushtaq et al. (2015) collected the data from 200 nurses for analyzing the impact of sexual harassment on their mental health in four public sectors hospitals of Lahore. They have found sexual harassment as a significant predictor of negative mental health in the form of depression, anxiety, and stress in nurses of public hospitals.

Shaikh (2000) conducted a study to understand the extent of sexual harassment of female nurses by different people in Islamabad public hospital. He has found that male physicians, patients and their relatives are the major committer of sexual harassment. It is recommended that nurses in their own capacity and hospital administration should protect nurses and provide them a secure work environment.

Khan et al. (2015) conducted a study with 150 nurses to assess the exposure rate by the type of harassment, awareness level of Sexual Harassment policy, contribution to raising voice and consequences on nurses and their performance at three tertiary care hospitals in Peshawar. Descriptive analysis was conducted and concluded that awareness about sexual harassment can lead toward a reduction in such incidences. Sexual harassment is found to have serious negative effects on nurse performance, health, morale, self-esteem and entire 
personality. They have recommended that Pakistan penal code about the protection of women at work place must be implemented truly. This law should also be made part in nursing education as well to enable them to fight against this evil more powerfully.

Audrey, J. (2010) tested a model for work place violence and sexual harassment for health care professionals predicting personal and organizational consequences. This model suggests that violence and sexual harassment leads to negative mental health. This includes fear, negative mood, perceived injustice which leads towards poor commitment and withdrawal intentions and poor performance in hospitals.

Chaudhri (2006) has also shared similar findings in health sector in Kolkata. He stated that sexual harassment is common in health sector and it basically refers to the norms of society about sexuality and masculinity in the work place. Attitude towards this among people is normal and considered to be harmless. This acts as a occupational hazard for the women.

\section{Methodology}

The population for the present study was the nurses working in the government hospitals of Lahore. One of the largest public hospitals in Lahore was selected as field of study and non probability sampling was used in which snow ball sampling has been used. This sampling design has been used as the willingness and availability of the respondents was very limited. Although researchers did build rapport with the nursing staff to understand maximum issues of their lives but respondents were reluctant to participate in this study in order to reveal the problems they were facing because of gender related issues. So in order to achieve maximum reliability and validity of our data we only took those nurses who were fully interested in the present study. And for that we used snowball or referential sampling design. We started with the data collection process with a nurse in the hospital and then develop contacts with other nurses.

We managed to have an inclusion criterion which was all those nurses who are regular employee of the hospital with at least three years for working experience. The reason for having this criterion is that they have an experience of working in the government hospital and quite aware of the working of the government hospital.

In depth interviews have been used a tool of data collection for the present study. As indepth interview relies on individuals in the research process and considers individuals as important and knowledgeable resources about the social world which can be shared through verbal communication (Hesse-Biber \& leavy, 2006).

Researchers did not have a complete interview guide. Questions were started generally about the problems which they are facing at hospital and then probed for more information for getting more relevant information. 
Three aspects were mainly discussed in the interviews. Socio-economic profile has been discussed in the interviews. Secondly nurses were interviewed about the life in public sector hospitals, their issues and concerns were discussed deeply. Third they were asked about the government policies regarding nursing staff. Fourth it has been discussed that how do they feel about themselves in the society. What is the response they get while being in the society?

Total 20 interviews have been conducted where it has been made sure that saturation level has been achieved and full information complete in all possible respects have been achieved. Interviews were conducted in Urdu language and then transcribed into English for further analysis.

Consideration of research ethics is most important concern for a social scientist. It's the moral and professional responsibility of the researcher to maintain the ethical standards. In the present research the researcher has followed all ethical considerations. The researcher has got prior permission from respondents for interviews and briefed them about the research objectives. The respondents were thoroughly briefed about the purpose of the research. The respondents have been told that their names would not be disclosed and all their information and discussion would be kept highly confidential. All interviews have been conducted after getting their approval.

\section{Data Analysis Procedure}

The researchers have used the following model in analysis and interpretation of qualitative data (Hesse-Biber \& Leavy 2006).

- Data Preparation

- Data Exploration

- Data Reduction

- Data Interpretation

\section{Data Preparation}

The data were collected in the form of in-depth interview. It was saved in the form of audio recording. The researchers have also taken field notes and maintain their dairy on daily basis. The researcher was very active in transcription of data on daily basis as it is very crucial to analysis and interpretation (Hasse-Biber \& Leavy 2006).

\section{Data Exploration}

In this phase the researcher has read the field notes and then listened to the recorded interview of the respondents very carefully. This practice was repeated several times. It has provided a chance to highlight important themes and inferences. The researcher has noted it down in a note book. This practice was very helpful to decide about most important themes and inferences. Through this practice the researcher has pointed out some very important quotes and put them in Italics in the data analysis. 


\section{Data Reduction}

Data reduction stage plays a significant role in coding of the data. In the present study the researcher has used Neuman's (2006) model for data coding

- Sorting and Classifying

- Open Coding

- Axial Coding

- Selective Coding

- Interpreting and Elaborating

\section{Data Interpretation}

In this stage the data were interpreted under different themes. Field observations and memo writing facilitated the researcher to create scientific text in the form of different themes and inferences (Hesse-Biber and Leavy 2006). The statements supporting the themes were quoted to provide evidence to the inferences. Most important quotes were given into boxes to highlight the imperative hidden meaning into local reality construction.

\section{Demographic and Socio-economic Profile of the Respondents}

Brief review of socio-economic and demographic profile is given below.

\section{Qualification}

\begin{tabular}{|l|l|l|}
\hline \hline Qualification & Number of nurses & Percentage \\
\hline Bsc Nursing & 20 & $100 \%$ \\
\hline Post RNA & 2 & $10 \%$ \\
\hline
\end{tabular}

\section{Marital Status}

\begin{tabular}{|l|l|l|}
\hline Marital Status & Number of nurses & Percentage \\
\hline Single & 14 & $70 \%$ \\
\hline Married & 4 & $20 \%$ \\
\hline Not Mentioned & 2 & $10 \%$ \\
\hline
\end{tabular}

Age

\begin{tabular}{|l|l|l|}
\hline \hline Age Group & Number of Nurses & Percentage \\
\hline $20-25$ & 7 & $35 \%$ \\
\hline $26-30$ & 8 & $45 \%$ \\
\hline $31-35$ & 5 & $25 \%$ \\
\hline
\end{tabular}

Above table shows the qualification, marital status and age of the respondents.

Their monthly income ranges from 35000-65000 which changes according to their span of job period. 


\section{Life at Hospital}

In this section following themes have been extracted which are being highlighting the issues which nurses are facing in the hospitals; at their work place.

\section{Nursing; A Very Tough Job}

This has been revealed from all the interviews that all the nurses repeatedly shared that their job is very tough and very demanding. They opinioned that it is fine to have a tough job routine but this always compensated with the reasonable salaries. So as their salaries are not in accordance with the services which they are performing so it becomes more hectic for all the nurses to perform. Job is also tough in a sense that it needs serious attention at the workplace for even all the minutes which nurses spent over there. They need to be all the time over anxious and concerned for the patients. Their job becomes tougher as they have to face the pressure from multiple sides the doctor side, the patients and their attendants. This is stated by all the respondents. Following are the comments shared by the respondents

"Our life is very tough; we have to remain all time attentive and concerned." For another instance one of the respondents said "we face pressure from many sides so that's why overall our job becomes really difficult."

This job is also tough in a way when we have to perform night duties. "Night duties are very hard to perform. We find so many problems while we are on night duties. For instance we are unable to find a transport which can take us to the hospital etc."

They sometime have to miss family functions and other gatherings because of this job. This adds up in the toughness of this job. Like a respondent said "I usually remain unable to attend family functions and other gatherings." Another respondent said "I usually miss my family functions because of night duties or other related emergencies."

\section{Harassment}

Sexual harassment is a very harsh problem in the workplace and a major social issue with serious negative effects (e.g. Richman et al., 1999).

Harassment is a most debated topic regarding females in any society. Developed countries have somehow made their workplace secure for their females. But in third world countries this is still a big issue for so many females. Fitzgerald (1993) found that sexual harassment remains prevalent in overall society throughout the history. He suggested that approximately 1 out of 2 women were harassed at some point during their 
academic and or working lives. He suggested that sexual harassment has psychological, health related and job related serious consequences.

Women working in low level jobs in our society faces more stereotypes and stigmas then other women who are working in some more sophisticated and upper level jobs. As nursing is also a white color job so nurses also face this problem at work place. So incidence of harassment is more frequent than in any other profession for females. Very confidentially nurses stated that the major problem which they face at work place is of the harassment. Harassment has multiple definitions and descriptions.

For instance Saeed (2003) states harassment as the abuse of Authority and creating Hostile Environment .It includes unwanted or unwelcome behavior, which can offend, humilities and intimated a person while creating un pleasent working environment Phillips (1993) said that "Sexual harassment is unwanted, unwelcome and rude behavior that makes you feel intimidated, victimized, uncomfortable, embarrassed, and threatened. It creates an intimidating, hostile or offensive environment for employment, study or social life. When this includes unwanted and unwelcome sexual advances, request for sexual favors or other verbal or physical conduct of a sexual nature, it is called Sexual Harassment."

Pryor (1995) reported that Sexual harassments can occur in a variety of situations. Often the harasser is in a position of power or authority over the victim (because of differences in age, or social, political, educational or employment relationships) or expecting to receive such power or authority in form of promotion.

Barton (1990) reported that sometimes sexual harassment takes a verbal form that is directed at the females like calling a women doll, babe, sweetie, etc. Sexually harassing conduct without words include looking at person's body, gazing at someone, blocking some one's path, following the person, giving gifts, hanging around a person, touching, make sexual gesture, messaging etc. These all different forms have been found in the nurses' interviews in varying capacity.

Here in this research study harassment is from many sides and this actually ruins the mental peace of the nurses at work place. As one respondent said "Mostly relatives of the patient harass the nurses. They have a habit of gazing at us. And use to pass comments loudly without any reason. They are also cracking silly jokes which are sometimes very shameful."

As many respondents have shared this view so this has been emerged as a theme out of all these interviews. 
The other side by which nurses are also being harassed is from the doctors' side. This has very different manifestation of the harassment. Respondents categorize it in different forms. Respondents describe different levels of harassment. Sometimes doctors explicitly ask for sexual favors. But sometimes considering us just females they try to create an environment which really irritates us. As a respondent expressed that "Just the fact we are females, they behave in a very awkward way. They keep on calling us with no reason, asking about the patients' condition unnecessarily. Simply they make a very difficult situation for us to work peacefully."

Another respondent opinioned "Doctors behave really badly. One thing which really irritates me is the unnecessarily touching of doctors to the nurses while handling them injections or other related items to the doctors."

On third dimension nurses discussed that how patients also harass the nurses. Nursing is a profession in which a close contact between the nurse and patient is required so sometimes it becomes unpleasant for nurses to handle patients. As one of the respondent quoted "Patients also behave in a pathetic way. They do not respect us. They call us unnecessarily with all lame excuses."

Above account shows that nurses face different kinds of harassment which includes, commenting, gazing, staring, discussing about the nurses' looks. So this happens with the nurses from multiple sides which have been elaborated above. According to them this has serious consequences for their mental and physical health and they feel unsecure at work place. They were of the opinion that they sometimes become extremely fearful because of these all situations.

Nurses also shared this view that they do not share these mishaps with any one because of multiple issues. This includes that they feel it troublesome to tell someone about the behavior of the patients, their attendants and the doctors. Nurses shared that change in work environment, leader trust; norms of society, their own attitude towards reporting can help themselves in reducing the chances of the harassment. These views are also supported by Clarke's findings. (2014)

\section{Views about Government Policies; Unavailability of Service Structure}

Nurses highlighted their main concern which is unavailability of service structure for the nursing staff. This has been a grave concern of the nursing staff and a bone of contention with the government. They were of the view point that there is no regard of higher qualification in the nursing field. Nurses who have done post RNA diploma or other diplomas they are not given any incentive. 
Other issue is that there is no procedure of promotion, regardless of the fact how many years one has served. There is no rapid promotion or even a defined way for the promotion of the nurses.

As a respondent shared "I have higher degree in nursing but do not have any benefit of that as in other departments where you have got higher education allowances".

"Our one of the very prime concern because of which we have launched so many strikes and protests is the unavailability of any service structure for the nurses."

Another respondent said "There is not a proper way for our promotion."

\section{Societal Response}

Nurses highlighted many concerns about society. Whatever they feel in society, its brief description is stated below. By society here means that how people generally behave toward them.

\section{Daunting Respect and Honor}

An important theme has been drawn from the nurses' discussion about how people behave toward them. They were of the view that they receive a mix kind of treatment from people. They respect us and give honor to them when they are in need. Like it happens that whenever they are having any emergency in their homes, they come and ask for help very politely but it's not the case otherwise. As a respondent exclaimed "It happens that whenever they (neighbors) need my help, their males truly calls me Sister but ironically they never give me respect as a sister."

As in Pakistan is traditional society where self medication and taking medicines on the advice of unqualified allopath is very common, so people usually take medicines on their own or with the little advice of any man who has just a any knowledge about medicines or the related things. So for that kind of help respondents referred in the interviews that when they need us they give respect to us otherwise not.

They also shared a view that "even though whole muhalla (Residential block) know that they (nurses) are nurses and they have to perform sometimes evening or night duties but still they never trust them fully. Like people are always susceptible toward them. Sharing her views about this issue a respondent said "I have to always make sure that whenever I have night duties my whole family especially cha-chas (Parental uncles) and my cousins must know that now a days I $m$ on night duty. With this close neighbors are also have to be reminded of that I am now a days on night duties." Another respondent said "My whole Muhalla (Residential Block) knows that I am a nurse but I really do not like their 
eyes when stare at me and the accents when they talk to me or talk to my family about myself. This is really unbearable."

\section{Marriage Issues}

As like other working women nurses also face many marital and family related problems which they highlighted. These were all common and like other females who are doing other jobs like the dual role which a working woman has to play, managing family, kids, in laws, husband. All married respondents highlighted the same issues. One thing which is very startling here that is the marriage prospects for the nurses. Respondents shared the point that they face relatively a tougher situation in getting an appropriate marriage proposal for them. The reasons according to the respondents were multiple. Among them is to find a suitable mate for the unmarried nurses is a basic problem. They do not find an appropriate mate who has a noble and respectable status in society. According to the respondents the reason is that society does not really give respect so they suffer all these problems.

\section{Discussion \& Conclusions}

The present study encompasses various dimensions of nurses' lives in Pakistan. There are multiple studies which describe the prevalence of sexual harassment and its impact on nurses' lives. This research goes beyond this point and covers some other aspects of the nurses' lives. This study broadly covers many areas of their lives. The themes have been extracted from in depth interviews which are mentioned above. For some themes researchers found some prior studies with them researchers found relevance some other issues which are being analyzed in this study are unique and quite new.

First of all their age, qualification and marital status have been described. Secondly some other aspects are also been discussed. Among them the first major category is described as the "Life at Hospital". In this category the first theme, extracted is the toughness of the job. All the respondents have shared that their job is very tough. This job requires full time dedication and commitment even sometime they are not able to fulfill their domestic responsibilities just because of the hardiness of the job. And even according to them this is not being compensated in a right manner with the salaries and other facilities. Second theme which has been emerged in this category is of harassment which remains common and is also supported by previous researches in the same field. (Malik et al (2014), Malik \& Farooqi (2014), Somani \& Khowaja (2012).

Like numerous studies cited above and other related studies it has been found that nurses become a serious victim of harassment. Present study has this capacity to elaborate the type of harassment which nurses face and secondly from various sources they face these 
kinds of advancements. This has been made clear in this study that nurses face sexual and general harassment from patients, their attendants and from doctors. In harassment includes asking for sexual favors, gazing, staring, passing comments, cracking immoral jokes, unnecessary touching etc. are included in the harassment. This is being also confirmed by the previous studies cited here. Malik et al. (2014), Malik \& Farooqi (2014), Somani \& Khowaja (2012). Nurses expressed deep concern about this harassment; sharing the view it has serious consequences for their mental and physical health. According to them this all leads to an uncomfortable work environment. They are uncertain about their own security at work place. It has been recommended by the nurses that their work environment must be made safe and sound so that's why they can work with all peace of mind. This idea is also supported by Yusufzai's (2006) study. Hamid (2010) also stated that in Pakistan the sexual harassment cases are very common but these cases are not usually reported, all the people have their own way to deal with it. Recently Government has passed a bill against sexual harassment. The purpose of this bill (2010) against sexual harassment to create the safe environment at working place free from harassment, abuse and intimidation. Code of sexual harassment is 509c and it is passed by Pakistan penal court in Last year (2010). The need is to encourage people to take serious steps for eradicating this problem.

Second category which has been emerged from these qualitative interviews was "Views about Government Policies" in which "unavailability of service structure" has been emerged as a theme. This theme is a new dimension in this study which has not been explored by the previous studies. Nurses clearly identified that government has not developed a road map for our promotion and has not given any other facilities. They are not getting higher qualification allowances as other people get in other fields. They said that one of the causes of frequent strikes of nurses is the unavailability of service structure by the government.

Third category was "Societal Response toward Nurses" in which daunting respect \& honor and marriage issues have been emerged. Nurses shared the view that they find an ambiguous situation in the society in the matter of respect and honor. People never give them a respectable status by heart. People give them respect whenever they need nurses in medical emergencies. Otherwise people never give them a respectable status. They shared that whole muhala (Residential block), (people from whole residential block) their uncles, cousins show unnecessary concern for their jobs and night duties. They pass weird looks to them and make their stay uncomfortable in different family gatherings. Other theme was of marriage related issues. First it's hard for the nurses and their families to find out a suitable marriage proposal for them as being nurse they are being viewed as inferior then females belonging to other professions. It's very hard for them to find a respectable and noble man for marriage. Mostly they get proposals from very down trodden families and those mostly unemployed or involve in immoral activities. Married 
women face usually the same issues as other working women face like dual burden of job and family responsibilities etc.

Present study precisely reveals many facts about the lives of nurse how they view their jobs, government policies and societal response towards them. Recommendations have been made that nurses should give a comfortable environment free from all kinds of harassment and distractions so they can work peacefully. The law against sexual harassment must be showed in hospitals so people remain careful about the act. Societal support must be given to the nurses so they can fully express their concerns about people with their seniors or family members. Government must settle all the issues with the nurses so they can work peacefully for promoting the health of the patients. New trends and initiatives must be taken for raising the status of the nurses in our society.

\section{References}

American Nursing Association (2016). http://www.nursingworld.org/EspeciallyForYou/ What-is-Nursing

Barton, Sarah (1995). The Impact of Sexual Harassment Simulations on Women's Thoughts and Feelings, Sex Roles, vol.30:10, pp.679-69.

Clarke, H. M. (2014). Predicting the Decision to Report Sexual Harassment: Organizational Influences and he Theory of Planned Behavior, Journal of Organizational Psychology, vol.14:2, p.53.

Ferdoos, A. (2005). Social Status of Rural and Urban Working Women in Pakistan A Comparative Study, Doctoral Dissertation Universitat Osnabruck.

Fitzgerald, L. F. (1993). Sexual Harassment: Violence against Women in the Workplace, American Psychologist, vol.48:10, p.1070.

Hamid, Rao. (2010). Senate Passes Bill against Harassment of Women at Workplace, Pakistan Daily Times Wire Service on 21, January, 2010. http://www.dailytimes.com.pk/

Hesse-Biber, S., \& Leavy, P. (2006). The Practice of Qualitative Research, Thousand Oaks, CA: Sage.

Human Development Reports, UNDP, (2015). http://hdr.undp.org/en/composite/GII 
Jayachandran, S. (2015). The Roots of Gender Inequality in Developing Countries, Annual Review of Economics, vol.7: Submitted. DOI: 10.1146/annureveconomics-080614-115404.

Khan, N., Begum, S. \& Shaheen, A. (2015). Sexual Harassment against Staff and Student Nurses in Tertiary Care Hospitals Peshawar KP Pakistan, International Journal of Innovative Research and Development, vol.4:1.

Malik, N, I. Malik, S. Qureshi, N. \& Atta, M. (2014). Sexual Harassment as Predictor of Low Self Esteem and Job Satisfaction among In-Training Nurses, FWU Journal of Social Sciences, vol.8:2, pp.107-116.

Malik, S., Farooqi, Y, N. (2014). General and Sexual Harassment as Predictors of Posttraumatic Stress Symptoms among Female Health Professionals, World Journal of Medical Sciences, vol.10:1, pp.43-49.

Mushtaq, M., Sultana, S., \& Imtiaz, I. (2015). The Trauma of Sexual Harassment and its Mental Health Consequences among Nurses, Journal of the College of Physicians and Surgeons--Pakistan: JCPSP, vol.25:9, pp.675-679.

National Commission for Justice and Peace (NCFJAP) (2007). CEDAW Shadow Report Pakistan. Lahore Pakistan.

Neuman, W. L. (2006). Analysis of Qualitative Data, Social Research Methods: Qualitative and Quantitative Approaches, pp.457-489.

Phillips, Susan (1993). Sexual Harassment of Female Doctors by Patients, Sexual Harassment, vol.34:8, pp.211-35.

Pryor, J. B. (1995). The Psychological Impact of Sexual Harassment on Women in the US Military, Basic and Applied Social Psychology, vol.17:4, pp.581-603.

Richman, J. A., Rospenda, K. M., Nawyn, S. J., Flaherty, J. A., Fendrich, M., Drum, M. L. \& Johnson, T. P. (1999). Sexual Harassment and Generalized Workplace Abuse among University Employees: Prevalence and Mental Health Correlates. American Journal of Public Health, vol.89, pp.358-363.

Royal College of Nursing (2009). Defining Nursing, Summary Leaflet London: RCN, Publication code 001983. 
Saeed, F. (2003). Guidelines for Creating Work Environment Free of Discrimination and Harassment: AASHA Islamabad.

Shaikh, M. A. (2000). Sexual Harassment in Medical Profession-Perspective from Pakistan, JOURNAL-PAKISTAN MEDICAL ASSOCIATION, vol.50:4, pp.130-131.

Somani, R. K. \& Khowaja, K. (2012). Workplace Violence towards Nurses: A Reality from the Pakistani Context, Journal of Nursing Education and Practice, vol.2:3.

World Bank (2014) Data Bank, http://data.worldbank.org/indicator/ SL.TLF.CACT.FE.ZS

Yusufzai, Ashfaq. "PAKISTAN: NURSES, IN SHORT SUPPLY, GET LITTLE TRAINING OR RESPECT." Inter Press Service English News Wire. IPS Inter Press Service News Agency (IPS). 2006. Retrieved January 17, 2016 from HighBeam Research: https://www.highbeam.com/doc/1P1$\underline{124736161 . h t m l}$

Dr. Lubna Karim Naz is an Assistant Professor in the Center for Media and Communication Studies, University of Gujrat.

Umar Rafique is an Associate Lecturer in the Department of Sociology, University of Gujrat. 